\title{
Long-chain SFA at the $s n-1,3$ positions of TAG reduce body fat deposition in C57BL/6 mice
}

\author{
Shiou Wah Gouk ${ }^{1}$, Sit Foon Cheng ${ }^{1 *}$, Josephine Shiueh Lian Mok $^{2}$, Augustine Soon Hock Ong ${ }^{1}$ \\ and Cheng Hock Chuah ${ }^{1}$ \\ ${ }^{1}$ Unit of Research on Lipids, Department of Chemistry, Faculty of Science, University of Malaya, \\ 50603 Kuala Lumpur, Malaysia \\ ${ }^{2}$ Department of Pharmacology, Faculty of Medicine, University of Malaya, 50603 Kuala Lumpur, Malaysia
}

(Submitted 3 August 2012 - Final revision received 9 April 2013 - Accepted 11 April 2013 - First published online 12 June 2013)

\section{Abstract}

The present study aimed to determine the effect of positional distribution of long-chain SFA in TAG, especially at the sn-1, 3 positions, on fat deposition using the C57BL/ 6 mouse model. Throughout the 15 weeks of the study, mice were fed with diets fortified with palm olein (POo), chemically interesterified POo (IPOo) and soyabean oil (SOY). Mice receiving the SOY-enriched diet gained significantly higher amounts of subcutaneous fat $(P=0.011)$ and total fat $(P=0.013)$ compared with the POo group, despite similar body mass gain being recorded. During normalisation with food consumption to obtain the fat:feed ratio, mice fed with the POo-enriched diet exhibited significantly lower visceral $(P=0.044)$, subcutaneous $(P=0.006)$ and total $(P=0.003)$ fat:feed than those fed with the SOY-enriched diet. It is noteworthy that mice fed with the IPOo-enriched diet gained $14.3 \%$ more fat per food consumed when compared with the POo group $(P=0.013)$, despite their identical total fatty acid compositions. This was mainly attributed to the higher content of longchain SFA at the $s n-1,3$ positions of TAG in POo, which results in delayed absorption after deacylation as evidenced by the higher amounts of long-chain SFA excreted in the faeces of mice fed with the POo-enriched diet. Negative correlations were found between the subcutaneous, visceral as well as total fat accretion per food consumption and the total SFA content at the $s n-1,3$ positions, while no relationships were found for MUFA and PUFA. The present results show that the positional distribution of long-chain SFA exerts a more profound effect on body fat accretion than the total SFA content.

Key words: Positional fatty acids: SFA: Fat deposition: Obesity

The prevalence of morbid obesity continues to be a major health threat to humans, as a result of which the WHO has termed obesity as alarming 'globesity'. In previous studies on rodents fed with obesogenic oils ${ }^{(1,2)}$, highly unsaturated soyabean oil ( $84.4 \mathrm{~g}$ unsaturated fatty acids/100 g total fatty acids) and sunflower oil $(89.7 \mathrm{~g}$ unsaturated fatty acids $/ 100 \mathrm{~g}$ total fatty acids) have been shown to result in a higher body fat content compared with palm oil and lard. Yet, this observation is not parallel with those of other studies that have used broiler chicken ${ }^{(3,4)}$ and rat ${ }^{(5,6)}$ models, in which it has been reported that sunflower oil significantly lowers fat accumulation when compared with beef tallow. On the other hand, the accumulation of fats in subcutaneous and visceral adipose tissues is highest in mice fed with a lard-enriched diet compared with those fed with diets fortified with olive, rapeseed and sunflower oils ${ }^{(7)}$. Generally, the intake of saturated fats has been perceived to exert deleterious effects on body fat deposition. Nonetheless, cocoa butter, a saturated fat, which has $63 \mathrm{~g}$ SFA/100 g total fatty acids, has been reported to prevent weight gain when compared with olive oil and safflower oil due to the presence of high amounts of palmitic and stearic acids ${ }^{(8)}$.

Based on the types of fatty acids present, SFA is responsible for higher rates of weight gain ${ }^{(9)}$, whereas PUFA, such as linoleic acid, do not induce obesity in $\mathrm{C} 57 \mathrm{BL} / 6 \mathrm{~J}$ mice ${ }^{(1)}$. Excessive intake of MUFA has deleterious effects that are similar to those caused by the intake of a diet rich in $\mathrm{SFA}^{(7)}$. A recent study has shown that there is a positive correlation between carcass fat content in rats and palmitic, stearic and oleic acids, and a negative correlation for linoleic acid ${ }^{(6)}$. The issue of the effect of n-6 PUFA, in particular linoleic acid, on obesity is controversial. In recent studies, linoleic acid has been shown to exert pro-obesity effects using rodents ${ }^{(2,10)}$; however, Matsuo et $a l .{ }^{(6)}$ postulated $n$-6 PUFA to be the most effective

Abbreviations: IPOo, chemically interesterified refined, bleached and deodorised palm olein; POo, refined, bleached and deodorised palm olein; SOY, refined, bleached and deodorised soyabean oil.

*Corresponding author: S. F. Cheng, fax +6037967 4193, email sfcheng@um.edu.my 
fatty acids in limiting the deposition of fats. A recent review article by Czernichow et al. ${ }^{(11)}$ has stated that the role of $n-6$ PUFA in obesity remains unclear as no conclusive inference can be drawn from the available epidemiological evidence. Although $n$-3 PUFA $^{(12,13)}$ have been claimed to reduce fat deposition, no conclusive results could be obtained by a recent systematic review of the evaluation of the effect of $n-3$ PUFA on body weight ${ }^{(14)}$.

There is no consistent inference that can be drawn from the relationship between TAG and obesity as most researchers have focused mainly on establishing the correlation between different dietary fatty acids or fats and distinct saturation levels. The effects of different levels of fat or the types of fats in the diet have been compared. Little attention has been paid to the effect of different rates of fat absorption due to the different positional distribution of fatty acids in TAG. Fatty acids at different $s n$-positions might not be subjected to the same rate of absorption. An individual consuming oils and fats is not only affected by the fatty acids, or saturation as a whole, but also by the chemical nature of TAG ${ }^{(15)}$. The positional distribution of fatty acids in the glycerol backbone is the key determinant of fat digestion and absorption ${ }^{(15,16)}$. A fatty acid at the $s n-2$ position is absorbed in the form of monoacylglycerols through intestinal mucosa after the action of 1,3-specific pancreatic lipase and those that are esterified at the $s n-1,3$ positions are absorbed as NEFA ${ }^{(16,17)}$. Prior literature has revealed that long-chain saturated NEFA suffer delayed absorption by virtue of the formation of $\mathrm{Ca}$ or $\mathrm{Mg}$ soaps ${ }^{(18-20)}$. This has led us to investigate the effect of positional fatty acid profile on fat deposition and obesity, using refined, bleached and deodorised palm olein (POo), chemically interesterified POo (IPOo) and refined, bleached and deodorised soyabean oil (SOY), which differ in the degree of fatty acid saturation levels at the $s n-1,3$ positions.

\section{Experimental methods}

\section{Diets}

POo of iodine value 56 was provided by Intercontinental Specialty Fats Sdn. Bhd. Chemically interesterified palm olein (IPOo, iodine value 56) was prepared from POo using sodium methoxide as a catalyst ${ }^{(21)}$. SOY was a generous gift from Soon Soon Oil Mills Sdn. Bhd. An autoclavable standard pellet feed (digestible energy $14.0 \mathrm{MJ} / \mathrm{kg}$ ) was purchased from Specialty Feeds. It was used as a diet for the control group without further fortification, whereas the other three test diets were fortified with POo, IPOo and SOY at an oil composition of $150 \mathrm{~g} / \mathrm{kg}$ diet (Tables S1-S4, available online). All test diets were isoenergetic $(20 \mathrm{MJ} / \mathrm{kg})$. The total fatty acid composition and positional fatty acids at the $s n-1,3$ and $s n-2$ positions of the test oils are given in Tables 1 and 2, respectively. The diets were prepared manually in the laboratory by mixing the pulverised standard diet pellets thoroughly with the test oils and thereafter pelleted to the original size and shape. The diets were then left to dry at $30^{\circ} \mathrm{C}$ in an oven overnight and stored at $4^{\circ} \mathrm{C}$ until use.
Table 1. Total fatty acid composition of the dietary oils and fats $(\mathrm{g} / 100 \mathrm{~g}$ total fatty acids)

\begin{tabular}{|c|c|c|c|}
\hline \multirow[b]{2}{*}{ Fatty acids } & \multicolumn{3}{|c|}{ Fatty acid composition } \\
\hline & POo & IPOo & SOY \\
\hline $12: 0$ & 0.26 & 0.27 & ND \\
\hline $14: 0$ & 1.00 & 1.01 & 0.07 \\
\hline $16: 0$ & $39 \cdot 30$ & 39.54 & 10.54 \\
\hline $18: 0$ & 4.36 & 4.37 & 4.28 \\
\hline $20: 0$ & 0.38 & 0.37 & 0.35 \\
\hline $22: 0$ & 0.04 & 0.07 & 0.38 \\
\hline Total SFA & $45 \cdot 30$ & 45.63 & $15 \cdot 62$ \\
\hline $16: 1 n-7$ & 0.16 & 0.17 & 0.08 \\
\hline $18: 1 n-9$ & $42 \cdot 70$ & $42 \cdot 48$ & $23 \cdot 84$ \\
\hline $20: 1 n-9$ & 0.15 & 0.13 & 0.21 \\
\hline Total MUFA & $43 \cdot 01$ & $42 \cdot 79$ & $24 \cdot 13$ \\
\hline $18: 2 n-6$ & 11.47 & $11 \cdot 36$ & 53.47 \\
\hline $18: 3 n-3$ & 0.22 & 0.22 & 6.77 \\
\hline $20: 2 n-6$ & ND & ND & ND \\
\hline Total PUFA & 11.68 & 11.58 & $60 \cdot 25$ \\
\hline
\end{tabular}

\section{Animal experiments}

A total of thirty-two weaned male $\mathrm{C} 57 \mathrm{BL} / 6$ mice (Monash University, Selangor, Malaysia) were randomly distributed into four groups of eight each and caged individually. The average body masses of the mice did not differ significantly after randomisation $(P=0.945)$, while they were 17.4 (SD 0.9), 17.9 (SD 1.0), $17 \cdot 3$ (SD 1.4) and 17.5 (SD 1.0) g when fed with the control, POo, IPOo and SOY diets, respectively. The animals were kept in rooms with adequate ventilation at $23 \pm 2^{\circ} \mathrm{C}$ and a relative humidity of $60 \%$ with a $12 \mathrm{~h}$ light $-12 \mathrm{~h}$ dark cycle. They were given ad libitum access to food and water.

The consumption of food and water was determined on a daily basis, whereas the body mass of the mice was recorded weekly. The actual food intake was corrected for spilled food after separation from the faeces of the mice. Fresh faeces were collected daily, pooled and stored at $-20^{\circ} \mathrm{C}$ for faecal analysis, starting from week 3 until week 15 . At the end of the study, mice were killed by dislocation of the neck. Subsequently, the subcutaneous and visceral fats were removed, weighed and kept frozen at $-80^{\circ} \mathrm{C}$. All protocols for the mouse experiments were approved by the Animal Care and Use Committee, Faculty of Medicine, University of Malaya, Kuala Lumpur, Malaysia (ethic no: KIM/23/03/2011/CSF (R)).

\section{Faecal lipids}

The extraction of fatty acids from faeces was carried out by using a modified method ${ }^{(22)}$. Briefly, $300 \mathrm{mg}$ of faeces were extracted with $15 \mathrm{ml}$ of chloroform-methanol (2:1, v/v) containing 10 parts per million of butylated hydroxytoluene. After overnight extraction, the solution was filtered and mixed with $4 \mathrm{ml}$ of $0.9 \% \mathrm{NaCl}$. It was then shaken and left overnight at $4{ }^{\circ} \mathrm{C}$ to remove aqueous impurities. The lower phase containing lipids was evaporated under reduced pressure on the next day and then methylated to form fatty acid methyl esters by acid-catalysed transesterification for fatty 
acid composition analysis ${ }^{(23)}$. The ratio of the composition of NEFA in the faeces to the composition of the individual fatty acids in the dietary oils (Table 1) was computed to represent the excretion index of each fatty acid.

\section{Lipid analysis}

The test oils and the NEFA extracted from the faeces were derivatised to fatty acid methyl esters by sodium methoxidecatalysed and sulphuric acid-catalysed transesterification, respectively $^{(23)}$. A methyl ester sample $(1 \mu \mathrm{l})$ was injected into a GC (GC-2010A series; Shidmadzu) equipped with a flame ionisation detector and a BPX70 capillary column of $30 \mathrm{~m} \times 0.32 \mathrm{~mm}$ inner diameter. An initial temperature of $140^{\circ} \mathrm{C}$ was held for $2 \mathrm{~min}$ and subsequently was increased to $220^{\circ} \mathrm{C}$ at a rate of $8^{\circ} \mathrm{C} / \mathrm{min}$. The column was held at the final temperature for $5 \mathrm{~min}$. The oven, injector and detector ports were set at 140,240 and $260^{\circ} \mathrm{C}$, respectively. Helium was used as the carrier gas with the column flow rate being $1 \cdot 10 \mathrm{ml} / \mathrm{min}$ at a $50: 1$ split ratio.

Regiospecific analysis of the test oils was conducted as described previously ${ }^{(24)} \cdot{ }^{13} \mathrm{C}$ NMR measurements were performed using a JEOL ECA- $400 \mathrm{MHz}$ NMR spectrometer (JEOL Ltd) operating at 9.4 T. Manual shimming was employed. A spectral width of $1500 \mathrm{~Hz}$ at which the acyl chain carbonyl carbons resonate, 8192 data points and $90^{\circ}$ pulse excitation were applied. The experimental temperature was set at $298.15 \mathrm{~K}$, whereas a repetition time of $34.5 \mathrm{~s}$ was chosen. The total number of scans per analysis was 128. Deconvolution was used as the integration method to separate the overlapped peak and calculate its area.

\section{Statistical analysis}

Data were subjected to IBM SPSS Statistic 20 (SPSS Inc.) for the statistical analysis. The significance level of differences among the dietary groups was assessed by one-way ANOVA. When significant differences were found, pairwise comparisons between groups were carried out by Fisher's least significant difference test, with one common standard error of the differences between means (SED) as the component for comparison. The accepted level of significance was $P<0.05$.

\section{Results}

Food consumption, body mass gain and body mass gain per $g$ feed

Throughout the 15 weeks (Table 3), all mouse groups, except the control group, showed comparable food consumption. Mice fed with the control diet, lacking fortified oils, served as the baseline for comparison. Different dietary oils exerted a similar effect on body mass gain and feed efficiency (body mass gain per $\mathrm{g}$ feed consumed). Food consumption and body mass gain at each week throughout the experimental period are given in Tables S1-S4 (available online).

\section{Fat deposited}

Mice receiving the SOY-enriched diet gained a significantly higher mass of subcutaneous fat $(P=0.011)$ and total fat $(P=0.013)$ compared with the POo group (Table 3$)$. The IPOo group exhibited a non-significant difference in terms of fat deposition compared with the SOY and POo groups. The fat-free masses of mice were not significantly different among the POo, IPOo and SOY dietary groups.

The mass of total fat deposited was further subjected to normalisation with total food consumption, denoted as fat:feed, to eliminate the effects of fat intake per se. Visceral fat:feed of mice fed with the POo-enriched diet was significantly lower $(P=0.044)$ than that of those fed with the SOY-enriched diet (Table 3), whereas no difference was found when compared with the IPOo group. In the context of total fat:feed, all groups differed significantly ( $P=0 \cdot 012$; Table 3$)$. Significantly higher subcutaneous fat:feed $(P=0.006)$ and total fat:feed $(P=0.003)$ were observed in the SOY group when compared with mice fed with the POo-enriched diet. It is noteworthy that chemical

Table 2. Positional fatty acid composition ( $\mathrm{mol} / 100 \mathrm{~mol}$ total fatty acids) of the dietary oils

(Mean values and standard deviations)

\begin{tabular}{|c|c|c|c|c|c|c|c|c|c|}
\hline \multirow[b]{4}{*}{ Samples } & \multirow[b]{4}{*}{ sn-position } & \multicolumn{8}{|c|}{ Composition (mol/100 mol total fatty acids) ${ }^{\star}$} \\
\hline & & & & \multicolumn{4}{|c|}{ MUFA } & & \\
\hline & & \multicolumn{2}{|c|}{ SFA } & \multicolumn{2}{|c|}{ cis-11-monoene $\dagger$} & \multicolumn{2}{|c|}{ cis-9-monoene } & \multicolumn{2}{|c|}{ PUFA } \\
\hline & & Mean & SD & Mean & SD & Mean & SD & Mean & SD \\
\hline \multirow[t]{3}{*}{ POo } & 1,3 & 71.0 & 0.4 & ND & ND & $26 \cdot 1$ & 0.3 & 2.9 & 0.3 \\
\hline & 2 & 7.4 & 0.9 & ND & ND & 74.3 & 0.9 & $18 \cdot 3$ & 0.2 \\
\hline & $1,2,3$ & $50 \cdot 3$ & 0.4 & ND & ND & $41 \cdot 8$ & 0.5 & 7.9 & 0.2 \\
\hline \multirow[t]{3}{*}{ IPOo } & 1,3 & $49 \cdot 6$ & 0.6 & ND & ND & $39 \cdot 9$ & 0.8 & $10 \cdot 5$ & 0.6 \\
\hline & 2 & $49 \cdot 0$ & 0.8 & ND & ND & $41 \cdot 0$ & 0.7 & $10 \cdot 0$ & 0.7 \\
\hline & $1,2,3$ & $49 \cdot 2$ & 0.8 & ND & ND & 40.5 & 0.8 & $10 \cdot 3$ & 0.6 \\
\hline \multirow[t]{3}{*}{ SOY } & 1,3 & $26 \cdot 3$ & 0.6 & 2.0 & 0.4 & $23 \cdot 4$ & 0.9 & $48 \cdot 3$ & 0.2 \\
\hline & 2 & ND & ND & ND & ND & $23 \cdot 8$ & 0.5 & $76 \cdot 2$ & 0.5 \\
\hline & $1,2,3$ & 17.5 & 0.4 & 1.3 & 0.3 & 23.5 & 0.6 & $57 \cdot 7$ & 0.1 \\
\hline
\end{tabular}

POo, palm olein; ND, not detected; IPOo, chemically interesterified POo; SOY, soyabean oil.

${ }^{*}{ }^{13} \mathrm{C}$ NMR results are the mean of three replicates.

$\dagger$ cis-11-monoene mainly consists of cis-vaccenic acid $(18: 1 n-7)^{(24)}$. 
Table 3. Different responses induced by various dietary oils in C57BL/6 mice over a 15-week experimental period (Mean values with their standard errors)

\begin{tabular}{|c|c|c|c|c|c|c|c|c|c|c|}
\hline & \multicolumn{2}{|c|}{ Control } & \multicolumn{2}{|c|}{ POo } & \multicolumn{2}{|c|}{ IPOo } & \multicolumn{2}{|c|}{ SOY } & \multirow[b]{2}{*}{ SED } & \multirow[b]{2}{*}{$P^{*}$} \\
\hline & Mean & SEM & Mean & SEM & Mean & SEM & Mean & SEM & & \\
\hline Food consumption† (g) & $357 \cdot 79^{a}$ & $10 \cdot 66$ & $327 \cdot 01^{b}$ & $2 \cdot 79$ & $315 \cdot 92^{b}$ & $7 \cdot 18$ & $322 \cdot 01^{b}$ & $5 \cdot 81$ & $10 \cdot 17$ & 0.0015 \\
\hline Body mass gain $(\mathrm{g})$ & $12 \cdot 85^{\mathrm{a}}$ & 1.06 & $18 \cdot 55^{\mathrm{b}}$ & 0.86 & $18 \cdot 96^{\mathrm{b}}$ & 0.59 & $19 \cdot 61^{\mathrm{b}}$ & $1 \cdot 14$ & 1.33 & 0.0001 \\
\hline Body mass gain:feed $\left(\times 10^{-2} \mathrm{~g} / \mathrm{g}\right)$ & $3.57^{\mathrm{a}}$ & 0.21 & $5 \cdot 67^{\mathrm{b}}$ & 0.23 & $6 \cdot 00^{\mathrm{b}}$ & 0.13 & $6 \cdot 07^{b}$ & 0.27 & 0.31 & $<0.0001$ \\
\hline Fat-free mass $(\mathrm{g})$ & $29 \cdot 34^{\mathrm{a}}$ & 0.99 & $33.55^{\mathrm{b}}$ & 0.91 & $32.54^{\mathrm{b}}$ & 0.57 & $33 \cdot 16^{\mathrm{b}}$ & 0.86 & $1 \cdot 20$ & 0.0059 \\
\hline \multicolumn{11}{|l|}{ Mass of fat } \\
\hline Subcutaneous (g) & $0.43^{\mathrm{a}}$ & 0.04 & $1.07^{\mathrm{b}}$ & 0.07 & $1 \cdot 25^{\mathrm{b}, \mathrm{c}}$ & 0.07 & $1 \cdot 38^{\mathrm{c}}$ & 0.12 & 0.11 & $<0.0001$ \\
\hline Visceral (g) & $0.39^{a}$ & 0.09 & $2 \cdot 25^{\mathrm{b}}$ & 0.06 & $2 \cdot 41^{\mathrm{b}}$ & 0.10 & $2 \cdot 49^{\mathrm{b}}$ & 0.15 & 0.15 & $<0.0001$ \\
\hline Total (g) & $0.82^{a}$ & $0 \cdot 10$ & $3 \cdot 32^{b}$ & 0.13 & $3.66^{b, c}$ & 0.11 & $3 \cdot 87^{c}$ & 0.22 & 0.21 & $<0.0001$ \\
\hline \multicolumn{11}{|l|}{ Mass of fat:feed } \\
\hline Subcutaneous fat:feed $\left(\times 10^{-3} \mathrm{~g} / \mathrm{g}\right)$ & $1 \cdot 20^{\mathrm{a}}$ & 0.13 & $3 \cdot 28^{\mathrm{b}}$ & 0.21 & $3.97^{\mathrm{c}}$ & 0.24 & $4 \cdot 29^{c, d}$ & 0.33 & 0.34 & $<0.0001$ \\
\hline Visceral fat:feed $\left(\times 10^{-3} \mathrm{~g} / \mathrm{g}\right)$ & $1 \cdot 14^{a}$ & 0.29 & $6 \cdot 87^{b}$ & 0.15 & $7 \cdot 62^{b, c}$ & 0.26 & $7.70^{c}$ & 0.38 & 0.40 & $<0.0001$ \\
\hline Total fat:feed $\left(\times 10^{-3} \mathrm{~g} / \mathrm{g}\right)$ & $2 \cdot 34^{\mathrm{a}}$ & 0.33 & $10 \cdot 14^{\mathrm{b}}$ & 0.35 & $11.59^{\mathrm{c}}$ & 0.28 & $11.99^{\mathrm{c}, \mathrm{d}}$ & 0.56 & 0.56 & $<0.0001$ \\
\hline
\end{tabular}

POo, palm olein; IPOo, chemically interesterified POo; SOY, soyabean oil.

a,b,c,d Mean values within a row with unlike superscript letters are significantly different $(P<0.05)$.

${ }^{*} P$ values were determined by one-way ANOVA.

†Food consumption was calculated as the total food intake for each mouse in 15 weeks and then averaged for each group $(n$ )

interesterification was associated with higher subcutaneous fat: feed and total fat:feed ( $P=0.049$ and 0.013 , respectively) as exhibited by mice fed with the IPOo-enriched diet when compared with those fed with the POo-enriched diet (Table 3). A negative linear correlation was observed between fat:feed and SFA content (mainly 16:0 and 18:0) at the $s n-1,3$ positions (Fig. 1(a)), while a positive linear correlation was found between fat:feed and the total unsaturated fatty acid content at the same positions (Fig. 1(b)). The correlation coefficients, $r$, fell in the range of 0.9076-0.9686. On the contrary, poor regressions were found for MUFA ( $r$ 0.1830-0.3578; Fig. 2(a)) and PUFA ( $r$ 0.7142-0.8289; Fig. 2(b)).

\section{Faecal fatty acids}

The composition of NEFA excreted in the faeces of mice in the present study is given in Table 4. The content of excreted linoleic acid (18:2n-6) was significantly higher in mice fed with the SOY-enriched diet compared with that in both the POo $(P<0.001)$ and IPOo $(P<0.001)$ groups. This finding was reflected in the total content of PUFA excreted by mice fed with the SOY-enriched diet, which accounted for $63.1 \%$ of total fatty acids. It is important to note that the content of excreted $\alpha$-linolenic acid $(18: 3 n-3)$ in the faeces of the SOY group differed significantly from that in the faeces of mice fed with the POo-enriched diet $(P=0.023)$, but no difference was found in mice fed with the IPOo-enriched diet. Total excretion of MUFA and SFA was significantly lower in the SOY group in comparison with the POo $(P=0.001$ and $P<0.001$, respectively) and IPOo $(P=0.001$ and $P<0.001$, respectively) groups.

Despite being fed with diets of an identical total fatty acid composition, mice fed with the POo-enriched diet excreted higher amounts of SFA $(P=0.019)$ compared with mice fed with the IPOo-enriched diet. The composition of 16:0 was higher $(P=0 \cdot 021)$ in the POo group, but no significant difference was found for the 18:0 content. In contrast, there was a substantially higher amount $(P=0.008)$ of MUFA, which mainly consisted of $18: 1 n-9$, being excreted by mice fed with the IPOo-enriched diet compared with the POo group. Such increment was also observed for PUFA excretion in the IPOo group, but the difference was not significant. The absolute amount of NEFA in the faeces of mice from the different dietary groups is given in Tables $\mathrm{S} 1-\mathrm{S} 4$ (available online).

Table 5 shows that mice fed with the POo-enriched diet had greater excretion indices of both major SFA (1.35 for 16:0 and 2.50 for $18: 0)$ in comparison with the IPOo group (1.14 for $16: 0$ and 2.34 for 18:0). This trend was reflected in the excretion index of total SFA (1.50 for POo and 1.32 for IPOo). It is interesting to note that the excretion of SFA with a longer chain length was greater than that of those with a shorter chain length. On the other hand, within a similar pairwise comparison, the IPOo group showed a concomitant increase in the excretion indices of total MUFA (18.0\% greater) and PUFA (35.9\% greater). Generally, the rate of fatty acid excretion for all the dietary oils is in the following order: SFA $>$ PUFA $>$ MUFA.

\section{Discussion}

The present study shows that the fatty acid composition at the $s n-1,3$ positions of the TAG molecule influences body fat accretion in $\mathrm{C} 57 \mathrm{BL} / 6$ mice. If long-chain SFA (16:0 and above) are present at the $s n-1,3$ positions, they tend to alleviate fat deposition, whereas they have no effect if present at the $s n$ - 2 position. In the duration of 15 weeks, mice from all the experimental groups (POO, IPOo and SOY) gained significantly higher fat and fat-free masses compared with the control group by virtue of the presence of fortified oils in their diets. The differences between the three experimental groups and the control group were more pronounced than the differences among the three experimental groups. It appears that the higher energy density in the test diets accounted for the remarkable changes in body composition. The total food consumption of all mice did not show any discrepancy, and all the test oils exerted the same effect on 

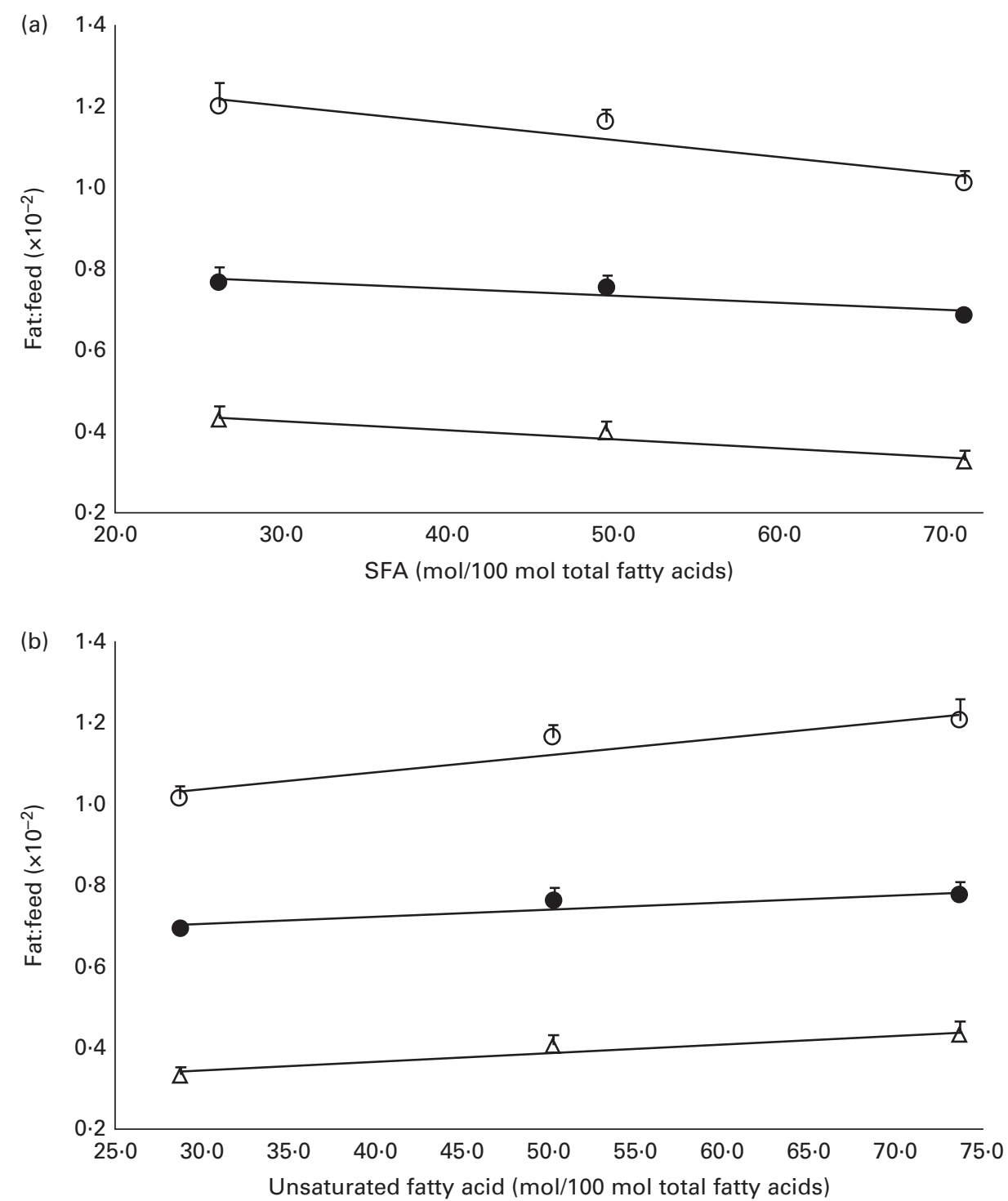

Fig. 1. Effect of total saturation levels at the $s n-1,3$ positions of TAG on fat deposition (mass of fat deposited:total feed consumed). Total fat:feed $(O, n 8)$, visceral fat:feed $(\bullet, n 8)$ and subcutaneous fat:feed $(\Delta, n 8)$ varied with (a) total SFA composition and (b) total unsaturated fatty acid composition at the sn-1, 3 positions. Values are means, with their standard errors represented by vertical bars. Correlation coefficients with $P$ values $<0.05$ were considered as significant. Total fat: feed: (a) $y=-0.0042 x+1.3296, \quad r=0.9404, P=0.038$; (b) $y=0.0042 x+0.9083, r=0.9404, P=0.058$. Visceral fat:feed: (a) $y=-0.0018 x+0.8267$, $r=0.9076, \quad P=0.033$; (b) $y=0.0018 x+0.6497, \quad r=0.9076, \quad P=0.043$. Subcutaneous fat:feed: (a) $y=-0.0022 x+0.4955, \quad r=0.9686, \quad P=0.038$; (b) $y=0.0022 x+0.2732, r=0.9686, P=0.072$.

the hunger and appetite of mice. The differences in body mass gain were insignificant across all the test groups, even after normalisation with food consumption (gain:feed) (Table 3). On the other hand, it was found that the different test oils had resulted in fat deposition to different extents in the subcutaneous and visceral tissues as well as total fat:feed (Table 3). Hence, the present study shows that body mass gain and fat deposition do not necessarily occur in tandem, and this clarifies the previous studies ${ }^{(1,8)}$, which used body mass gain as the marker for obesity. We, therefore, focused on normalisation data (Table 3), namely fat:feed, in the present evaluation of diet-induced adipogenic oils. As a whole, in the context of obesity risk factor, the present study shows that the SOY- and IPOo-enriched diets exhibit a higher potential towards obesity risk compared with a POo-enriched diet.
Feeding of the SOY-enriched diet ( $17.5 \mathrm{~mol} \mathrm{SFA} / 100 \mathrm{~mol}$ total fatty acids) for 15 weeks induced significantly higher fat deposition when compared with that of the POo-enriched diet ( $50.3 \mathrm{~mol} \mathrm{SFA} / 100 \mathrm{~mol}$ total fatty acids), which is in agreement with previous reports that have compared both ${ }^{(2,10)}$. However, this contradicts the reports ${ }^{(3-6)}$ that have generalised that any increase in fat deposition is correlated with the amount of saturation in the oil; that is, an oil with a higher saturation content results in more fat deposition when compared with a lower saturated (or higher unsaturated) oil, based on studies that have used sunflower oil and beef tallow. This inconsistency can be elucidated by looking at the positional distribution of SFA in the oils being studied. Beef tallow contains about $33.6 \mathrm{~g}$ SFA $/ 100 \mathrm{~g}$ and $79.4 \mathrm{~g} \mathrm{SFA} / 100 \mathrm{~g}$ total fatty acids at the $s n-1,3$ and $s n-2$ positions, respectively ${ }^{(25)}$, while POo used in the 

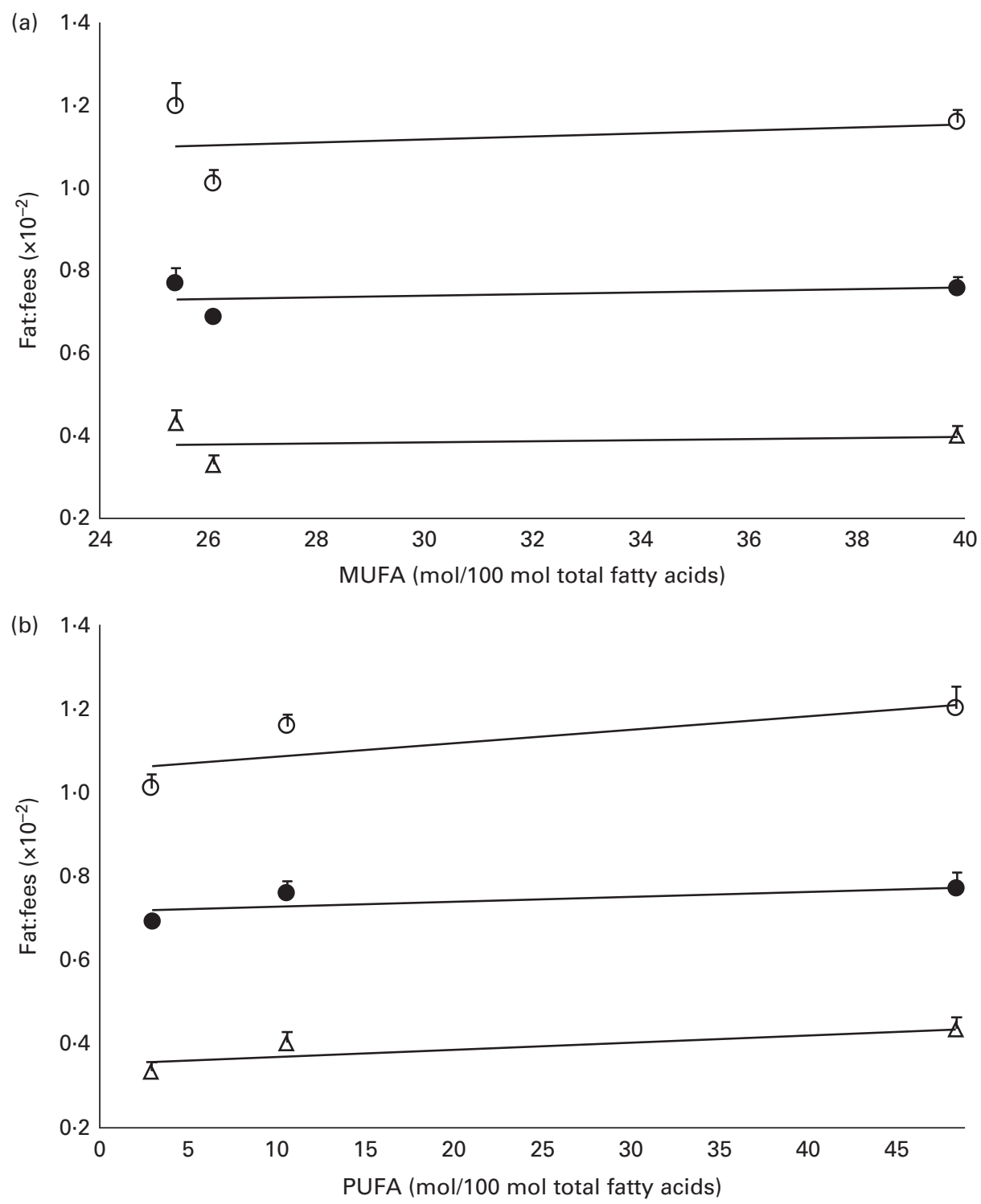

Fig. 2. Effect of different unsaturation levels at the $s n-1,3$ positions of TAG on fat deposition (mass of fat deposited:total feed consumed). Total fat:feed (O, $n 8$ ), visceral fat:feed $(\bullet, n 8)$ and subcutaneous fat:feed $(\Delta, n$ 8) varied with (a) total MUFA composition and (b) total PUFA composition at the sn-1, 3 positions. Values are means, with their standard errors represented by vertical bars. Correlation coefficients with $P$ values $<0.05$ were considered as significant. Total fat: feed: (a) $y=0.0034 x+1.0203, r=0.2760, P=0.822$; (b) $y=0.0032 x+1.058, r=0.7717, P=0.439$. Visceral fat:feed: (a) $y=0.0019 x+0.6819, r=0.3578$, $P=0.767$; (b) $y=0.0013 x+0.7137, r=0.7142, P=0.494$. Subcutaneous fat:feed: (a) $y=0.0011 x+0.3517, r=0.1830, P=0.883 ;$ (b) $y=0.0017 x+0.3507$, $r=0.8289, P=0.378$.

present study contains $71 \cdot 0 \mathrm{~mol}$ SFA $/ 100 \mathrm{~mol}$ total fatty acids at the $s n-1,3$ positions and $7 \cdot 4 \mathrm{~mol} \mathrm{SFA} / 100 \mathrm{~mol}$ total fatty acids at the $s n$-2 position (Table 2 ). Based on the present study, we postulate that if higher amounts of long-chain SFA are present at the $s n-1,3$ positions, they tend to alleviate fat deposition.

By investigating the types of fat deposition, we found that the SOY-enriched diet resulted in a significantly higher deposition of visceral fat:feed compared with the POo-enriched diet (Table 3). This significant difference, which may provide some prospective benefits in getting a healthy diet as visceral adiposity is associated with various health problems, including CVD, insulin resistance, hypertension, breast and endometrial cancers, and overall mortality ${ }^{(26,27)}$, should be confirmed in future clinical trials.
It was noted that the differences in fat deposition were significant between the POo and SOY groups, but not in the pairwise comparison between the IPOo and SOY groups (Table 3). Despite identical total saturation and unsaturation levels, mice fed with the IPOo-enriched diet gained 14.3\% more fat per food consumed compared with the POo group. As shown in Table 2, the saturated content at the $s n-1,3$ positions in POO was $21.4 \mathrm{~mol} \%$ higher than that in IPOo. This observation supported our postulation that a lower SFA content at the $s n-1,3$ positions in IPOo was responsible for the higher fat absorption, TAG resynthesis in chylomicrons and eventually deposition in the mice. Mostly free SFA that deacylated from the $s n-1,3$ positions of POo suffered delayed absorption and formed $\mathrm{Ca}$ soaps and then subsequently were excreted from the body as 
Table 4. Composition of NEFA ( $\mathrm{g} / 100 \mathrm{~g}$ total fatty acids) in the faeces of mice in each test group (Mean values and standard deviations)

\begin{tabular}{|c|c|c|c|c|c|c|c|c|c|c|}
\hline Fatty acids & Mean & SD & Mean & SD & Mean & SD & Mean & SD & SED & $P^{*}$ \\
\hline $14: 0$ & $2 \cdot 26^{a}$ & 0.16 & $1 \cdot 24^{\mathrm{b}}$ & 0.05 & $1 \cdot 13^{b}$ & 0.08 & $0.75^{\mathrm{b}}$ & 0.04 & 0.19 & 0.0062 \\
\hline $16: 0$ & $24.98^{a}$ & 1.41 & $52.97^{b}$ & 0.95 & $44.92^{c}$ & 1.29 & $14 \cdot 43^{d}$ & 1.82 & $2 \cdot 19$ & 0.0002 \\
\hline $22: 0$ & 1.58 & 0.09 & 1.05 & 0.44 & 1.92 & 0.23 & 0.92 & 0.10 & 0.39 & 0.1706 \\
\hline Total SFA & $38 \cdot 34^{a}$ & 1.98 & $67 \cdot 83^{b}$ & 0.20 & $60 \cdot 17^{c}$ & $2 \cdot 23$ & $23 \cdot 15^{d}$ & 1.01 & 2.02 & 0.0001 \\
\hline $16: 1 n-7$ & ND & ND & 0.19 & 0.27 & ND & ND & 0.10 & 0.01 & 0.15 & 0.5918 \\
\hline $18: 1 n-9$ & $27 \cdot 04^{a}$ & 0.79 & $20 \cdot 70^{b}$ & 0.70 & $24 \cdot 65^{c}$ & $1 \cdot 22$ & $13 \cdot 29^{d}$ & 0.05 & 0.80 & 0.0003 \\
\hline $20: 1 n-9$ & $0.90^{a}$ & 0.07 & $0.53^{b}$ & 0.10 & $0 \cdot 70^{a, b}$ & 0.15 & $0.35^{\mathrm{b}}$ & 0.12 & 0.11 & 0.0337 \\
\hline Total MUFA & $27 \cdot 94^{a}$ & 0.86 & $21.41^{b}$ & 0.86 & $25 \cdot 35^{c}$ & 1.06 & $13 \cdot 75^{d}$ & 0.08 & 0.81 & 0.0002 \\
\hline
\end{tabular}

POo, palm olein; IPOo, chemically interesterified POo; SOY, soyabean oil; ND, not detected.

a,b,c,d Mean values within a row with unlike superscript letters are significantly different $(P<0.05)$.

suggested previously ${ }^{(19,20)}$. This is further supported by the greater excretion indices of palmitic and stearic acids in the faeces of mice fed with the POo-enriched diet, which are 18.4 and $6.8 \%$, respectively, which are higher than those of the acids in the faeces of mice fed with the IPOo-enriched diet (Table 5), and this is consistent with the trend reported by other researchers ${ }^{(18)}$. Furthermore, encouraging reductions in subcutaneous and total fat deposition in mice fed with the POo-enriched diet when compared with those fed with the IPOo-enriched diet were observed, despite their comparable total fatty acid compositions. This has never been disclosed and might possess the potential to surpass previous studies $^{(1-10)}$, which have investigated the adipogenic effect of oils merely based on total SFA, MUFA or PUFA contents.

According to reported data ${ }^{(16,1819)}$, after the action of pancreatic lipase, long-chain SFA that are liberated from the $s n-1,3$ positions are poorly absorbed and subsequently excreted in the form of $\mathrm{Ca}$ or Mg NEFA salts. This was further proven in the present investigation. When the fatty acids in the faeces were normalised with their respective composition in the ingested fats (Table 5), an interesting trend was observed for total SFA, PUFA and MUFA. All the excretion indices were somewhat similar regardless of the type of ingested fats. Major MUFA, namely oleic acid, were found to be less readily excreted as they were well absorbed in the intestine. In contrast, the relative compositions of all types of SFA in the faeces were greater than those of the corresponding fatty acids in dietary fats. For efficient absorption, micelles formed by the bile salts take up the non-polar NEFA to permit their transport across the aqueous boundary layer of the intestinal wall. Thus, long-chain SFA, which are relatively more non-polar than unsaturated fatty acids, have been observed to be less susceptible to intestinal absorption. The susceptibility of fatty acids to absorption in the intestine in an increasing order is as follows: SFA; PUFA; lastly the most absorbed MUFA.

Using our postulation, several previous contradicted reports can be further generalised and elucidated. Conventional saturated fats, namely palm oil ${ }^{(1)}$ and cocoa butter ${ }^{(8)}, v$. beef tallow $^{(3-6,9)}$ and $\operatorname{lard}^{(7)}$ have been reported to exert diverse adipogenic effects. Palm oil and cocoa butter, which have been found to be less obesogenic, contain SFA mainly at the $s n-1,3$ positions, whereas major SFA are present at the $s n-2$ position of the TAG moiety in beef tallow and lard ${ }^{(25)}$. Thus, the positive correlation between SFA composition and carcass fat content found in a previous study, which used beef tallow as the sole major source of $\mathrm{SFA}^{(6)}$, might not be valid as a similar investigation is being conducted on cocoa butter. On the other hand, excessive intake of MUFA has been reported to exert detrimental effects on fat deposition ${ }^{(7)}$, which can be correlated with the higher rate of absorption (lower rate of excretion) of MUFA found in the present study. From the perspective of positional fatty acids at the $s n-1,3$ positions in the TAG molecule, a positive correlation was observed between total fat:feed and the unsaturated content, whereas a negative correlation was found between fat:feed and the total SFA content (Fig. 1). There was

Table 5. Excretion indices of each fatty acid in the faeces of mice in the different dietary groups

\begin{tabular}{lcccc}
\hline Fatty acids & Control & POo & IPOo & SOY \\
\hline $12: 0$ & ND & 0.34 & ND & ND \\
$14: 0$ & $2 \cdot 22$ & 1.24 & 1.12 & 1.06 \\
$16: 0$ & 1.75 & 1.35 & 1.14 & 1.37 \\
$18: 0$ & 2.58 & 2.50 & 2.34 & 1.43 \\
$20: 0$ & 3.32 & 4.10 & 5.24 & 2.60 \\
$22: 0$ & 3.16 & 26.23 & 28.57 & 2.45 \\
Total SFA & 2.05 & 1.50 & 1.32 & 1.48 \\
$16: 1 n-7$ & ND & 1.16 & ND & 1.32 \\
$18: 1 n-9$ & 0.79 & 0.48 & 0.58 & 0.56 \\
$20: 1 n-9$ & 1.33 & 3.56 & 5.19 & 1.68 \\
Total MUFA & 0.80 & 0.50 & 0.59 & 0.57 \\
$18: 2 n-6$ & 0.75 & 0.86 & 1.16 & 1.15 \\
$18: 3 n-3$ & 0.61 & 4.40 & 5.99 & 0.27 \\
Total PUFA & 0.73 & 0.92 & 1.25 & 1.05 \\
\hline
\end{tabular}

POo, palm olein; IPOo, chemically interesterified POo; SOY, soyabean oil; ND, not detected. 
no relationship found between fat deposition and linoleic acid content in the present study (Fig. 2).

In addition, Ponnampalam et al. ${ }^{(28)}$ observed a slightly lower fat percentage $(20.5 \%)$ in piglets fed with a diet containing natural palm olein compared with those fed with a diet containing lard (21.2\%) and chemically interesterified palm olein (21.5\%). A recent study has also shown that the dietary 1(3)-behenoyl-2,3(1)-dioleoylglycerol, which contains longchain saturated behenic acid $(22: 0)$ at the $s n-1$ or $s n-3$ position, prevents the deposition of visceral fat and hepatic TAG ${ }^{(29)}$. With no explicit reason being given previously, our postulation is expected to provide more insights into the effect of positional distribution of long-chain SFA on fat deposition.

On the other hand, the analysis on fatty acid composition of adipose tissue (data not shown) showed that there was a greater degree of fatty acid deposition for MUFA, followed by PUFA and lastly by SFA. This is in accordance with the excretion index of fatty acids, which is greatest for SFA, followed by PUFA and lowest for MUFA (Table 5). The deposited fatty acids are highly correlated with those absorbed through the intestine after the action of pancreatic lipase, which further elucidates the rate of absorption of different fatty acids and eventually the effect on fat deposition. Some minor fatty acids, particularly myristic (14:0) and palmitoleic (16:1n-7) acids, were found abundantly in both subcutaneous and visceral adipose tissues, suggesting de novo synthesis ${ }^{(30)}$.

In conclusion, we demonstrated that the positional distribution of long-chain SFA and not the total SFA content exerts a more profound effect on body fat accretion. If longchain SFA (16:0 and above) are present at the $s n-1,3$ positions, they tend to reduce fat deposition. Consequently, the amount of resynthesised TAG is reduced, affecting their incorporation in lipoproteins and subsequent metabolism, their distribution into tissues and eventually the extent of fat deposition. Due to the observation of greater excretion indices for a longer chain length, there might be a further alleviation of fat deposition if longer chains of SFA, for instance, 18:0, $20: 0$ and $22: 0$, are present mainly at the $s n-1,3$ positions, and this warrants further investigation.

\section{Supplementary material}

To view the supplementary material for this article, please visit http://dx.doi.org/10.1017/S0007114513001475

\section{Acknowledgements}

The present study was supported by the Ministry of Higher Education Malaysia, through the Fundamental Research Grant Scheme (grant no. FP011/2010A). All authors were responsible for the design and execution of the study. S. W. G. performed the hands-on experiments, namely, the animal study, sample analyses and statistical analyses. S. W. G., S. F. C. and C. H. C. wrote the manuscript. J. S. L. M. and A. S. H. O. reviewed, read and approved the final version. The authors have no conflicts of interest to declare.

\section{References}

1. Ikemoto S, Takahashi M, Tsunoda N, et al. (1996) High-fat diet-induced hyperglycemia and obesity in mice: differential effects of dietary oils. Metabolism 45, 1539-1546.

2. Stachon M, Furstenberg E \& Gromadzka-Ostrowska J (2006) Effects of high-fat diets on body composition, hypothalamus NPY, and plasma leptin and corticosterone levels in rats. Endocrine 30, 69-74.

3. Sanz M, Lopez-Bote CJ, Menoyo D, et al. (2000) Abdominal fat deposition and fatty acid synthesis are lower and $\beta$-oxidation is higher in broiler chickens fed diets containing unsaturated rather than saturated fat. J Nutr 130, 3034-3037.

4. Newman RE, Bryden WL, Fleck E, et al. (2002) Dietary $n-3$ and $n-6$ fatty acids alter avian metabolism: metabolism and abdominal fat deposition. Br J Nutr 88, 11-18.

5. Shimomura Y, Tamura T \& Suzuki M (1990) Less body fat accumulation in rats fed a sunflower oil diet than in rats fed a beef tallow diet. J Nutr 120, 1291-1296.

6. Matsuo T, Takeuchi H, Suzuki H, et al. (2002) Body fat accumulation is greater in rats fed a beef tallow diet than in rats fed a safflower or soybean oil diet. Asia Pacific $J$ Clin Nutr 11, 302-308.

7. Catta-Preta M, Martins MA, Brunini TMC, et al. (2012) Modulation of cytokines, resistin, and distribution of adipose tissue in $\mathrm{C} 57 \mathrm{BL} / 6$ mice by different high-fat diets. Nutr $\mathbf{2 8}$, $212-219$.

8. Timmers S, de Vogel-van den Bosch J, de Wit N, et al. (2011) Differential effects of saturated versus unsaturated dietary fatty acids on weight gain and myocellular lipid profiles in mice. Nutr Diabetes 1, e11.

9. Larson DE, Hunter GR, Williams MJ, et al. (1996) Dietary fat in relation to body fat and intraabdominal adipose tissue: a cross-sectional analysis. Am J Clin Nutr 64, 677-684.

10. Jen KL, Buison A, Pellizzon M, et al. (2003) Differential effects of fatty acids and exercise on body weight regulation and metabolism in female Wistar rats. Exp Biol Med 228, 843-849.

11. Czernichow S, Thomas D \& Bruckert E (2010) n-6 Fatty acids and cardiovascular health: a review of the evidence for dietary intake recommendations. Br J Nutr 104, 788-796.

12. Okuno M, Kajiwara K, Imai S, et al. (1997) Perilla oil prevents the excessive growth of visceral adipose tissue in rats by down-regulating adipocyte differentiation. J Nutr $\mathbf{1 2 7}$, $1752-1757$

13. Micallef M, Munro I, Phang M, et al. (2009) Plasma $n$-3 polyunsaturated fatty acids are negatively associated with obesity. Br J Nutr 102, 1370-1374.

14. Martinez-Victoria E \& Yago MD (2012) Omega 3 polyunsaturated fatty acids and body weight. BrJ Nutr 107, S107-S116.

15. Ong ASH \& Goh SH (2002) Palm oil: a healthful and costeffective dietary component. Food Nutr Bull 23, 11-22.

16. Small DM (1991) The effects of glyceride structure on absorption and metabolism. Annu Rev Nutr 11, 413-434.

17. Kayden HJ, Senior JR \& Mattson FH (1967) The monoglyceride pathway of fat absorption in man. J Clin Invest 46, 1695-1703.

18. Brink EJ, Haddeman E, de Fouw NJ, et al. (1995) Positional distribution of stearic acid and oleic acid in a triacylglycerol and dietary calcium concentration determines the apparent absorption of these fatty acids in rats. J Nutr 125, 2379-2387.

19. Mattson FH, Nolen GA \& Webb MR (1979) The absorbability by rats of various triglycerides of stearic and oleic acid and the effect of dietary calcium and magnesium. J Nutr 109, 1682-1687.

20. Innis SM, Dyer RA \& Lien EL (1997) Formula containing randomized fats with palmitic acid (16:0) in the 2-position 
increases 16:0 in the 2-position of plasma and chylomicron triglycerides in formula-fed piglets to levels approaching those of piglets fed sow's milk. J Nutr 127, 1362-1370.

21. Lo YC \& Handel AP (1983) Physical and chemical properties of randomly interesterified blends of soybean oil and tallow for use as margarine oils. $\mathrm{J} \mathrm{Am} \mathrm{Oil} \mathrm{Chem} \mathrm{Soc}$ 60, 815-818.

22. Folch J, Lees M \& Sloane Stanley GH (1957) A simple method for the isolation and purification of total lipides from animal tissue. J Biol Chem 226, 497-509.

23. Christie WW (1989) Gas Chromatography and Lipids: A Practical Guide. Bridgwater: The Oily Press Ltd.

24. Gouk SW, Cheng SF, Ong ASH, et al. (2012) Rapid and direct quantitative analysis of positional fatty acids in triacylglycerols using ${ }^{13} \mathrm{C}$ NMR. Eur J Lipid Sci Technol 114, 510-519.

25. Gunstone FD \& Harwood JL (2007) Occurrence and characterisation of oils and fats. In The Lipid Handbook, 3rd ed., pp. 92-108 [FD Gunstone, JL Harwood and AJ Dijkstra, editors]. Boca Raton, FL: CRC Press.
26. Emery EM, Schmid TL, Kahn HS, et al. (1993) A review of the association between abdominal fat distribution, health outcome measures, and modifiable risk factors. Am J Health Promot 7, 342-353.

27. Kim MK, Jang EH, Son JW, et al. (2011) Visceral obesity is a better predictor than generalized obesity for basal insulin requirement at the initiation of insulin therapy in patients with type 2 diabetes. Diabetes Res Clin Pract 93, 174-178.

28. Ponnampalam EN, Lewandowski $\mathrm{P}$, Nesaratnam K, et al. (2011) Differential effects of natural palm oil, chemicallyand enzymatically-modified palm oil on weight gain, blood lipid metabolites and fat deposition in a pediatric pig model. Nutr J 10, 53.

29. Kojima M, Tachibana N, Yamahira T, et al. (2010) Structured triacylglycerol containing behenic and oleic acids suppresses triacylglycerol absorption and prevents obesity in rats. Lipids Health Dis 9, 77-82.

30. Perona JS, Portillo MP, Macarulla MT, et al. (2000) Influence of different dietary fats on triacylglycerol deposition in rat adipose tissue. Br J Nutr 84, 765-774. 